\title{
Deduction of Surfactants Effect on Performance, Morphology, Thermal and Molecular Properties of Polymeric Polyvinylidene Fluoride (PVDF) Based Ultrafiltration Membrane
}

\author{
Nurul Hannan Mohd Safari ${ }^{1}$, Abdul Rahman Hassan ${ }^{1,2^{*}}$, Che Wan Insyirah Che Wan Takwa', \\ Sabariah Rozali ${ }^{1}$ \\ ${ }^{1}$ East Coast Environmental Research Institute, Universiti Sultan Zainal Abidin, 21300 Kuala Nerus, Terengganu, Malaysia \\ 2 Department of Manufacturing Technology, Faculty of Innovative Design and Technology, Universiti Sultan Zainal Abidin, \\ 21300 Kuala Nerus, Terengganu, Malaysia \\ * Corresponding author, e-mail: rahmanhassan@unisza.edu.my
}

Received: 18 April 2018, Accepted: 19 July 2018, Published online: 31 August 2018

\begin{abstract}
In membrane making, surfactant material is one of the effective strategies to produce membrane / thin film with optimal and specific properties. This paper addressed the effect of Sodium dodecyl sulphate (SDS), Triton X-100 and Tween 80 as additives for the making of Polyvinylidene fluoride (PVDF) ultrafiltration (UF) membranes. The fabricated membranes were analysed in the aspect of performance, morphological structures, thermal properties and molecular orientation. Analysis results showed that the surfactant additives enhanced the membrane performance and properties. Surprisingly, the addition of 2 wt\% surfactant increased the permeate flux of bovine serum albumin (BSA) up to $78.14 \mathrm{~L} / \mathrm{m}^{2} \mathrm{~h}$ compared to membrane without surfactant with flux at only $2.74 \mathrm{~L} / \mathrm{m}^{2} \mathrm{~h}$. In addition, the role of surfactants on membrane pores and pore properties of PVDF UF membranes were examined. The cross-sectional morphological structures showed that these surfactants led towards the formation of macro-voids and finger-like structures as well as a spongy layer. The surfactants additives also improved the membrane pores and pore properties which reflect to the protein rejection up to $85 \%$ and $78 \%$ of BSA and egg albumin (EA), respectively. Moreover, analysis on the thermal features found that SDS, Triton X-100 and Tween 80 promoted better thermal stability and significantly fine molecular alignment which provided the versatility for the membrane to be used for any applications.
\end{abstract}

Keywords

ultrafiltration, surfactant, morphology, thermal stability, molecular

\section{Introduction}

One of the key performances of the asymmetrical membranes ultrafiltration process is determined by their morphological structures. There are three types of membrane structures can be formed during fabrication process, depending on its kinetic and thermodynamic parameters: i) a symmetric structure with uniform porosity across the membrane cross-sectional was acquired when the rate of polymer precipitation is low; ii) an asymmetric membrane, which consists of a thin microporous upper layer and a thick macro-porous, spongy sub-layer; iii) an asymmetric structure with micro-porous upper layer along with finger-like and large voids beneath the skin layer when the rate of precipitation is high $[1,2]$.
The preparation of asymmetric membrane structure commonly produced via phase inversion technique [3, 4]. This technique is responsible to form typical asymmetric character, which involving skin (upper) and support (bottom) layer with a dense spongy structure occupied beneath the skin layer [5]. The fabrication technique in the improvement of membrane morphologies has been discussed by many researchers. However, the problem regarding this issue still not resolved completely due to the difficulties in materials selection and fabrication of membrane with good properties and operation for various applications. For example, the selection of solvent like N-methyl-2-pyrrolidone (NMP), Dimethylacetamide (DMAc), Dimethylformamide 
(DMF) and Dimethyl sulfoxide (DMSO) in the solution system [6], the concentration and types of polymer such as polyvinylidene fluoride (PVDF), polyethersulfone (PES) and polysulfone (PSF) [7] and the types of non-solvent system [8]. Furthermore, introducing of a proper additive such as organic, inorganic additive, surfactant, polymer, mineral fillers etc. into the system $[1,9]$ and controlling the condition of the film casting $[4,10]$ also play a significant part to modify the final morphology.

Finger-like cavities formed when the rate of solvent-non-solvent exchange during the phase inversion is faster. Spongy-like structures exist when the rate of solvent-non-solvent exchange is slower [11]. Larger finger-like pores might be caused the intrinsic membrane resistance decrease. It must be noted that by decreasing the intrinsic membrane resistance, the permeability of water will be increased [4, 12]. However, it was reported that the longer and larger finger-like voids with the presence of dense spongy-like structures reduced the volume flux, provided good mechanical strength and better rejection [10]. Good membrane structure consists of well-developed finger-like, a dense top-layer and spongy sub-layer [13] that will provided high permeate flux and rejection selectivity [14]. These structures also increase the span life of the membranes by lowered the chances of membrane fouling either reversible or irreversible fouling [15] by solute adsorption, particle deposition or membrane blocking [14].

The presence of macro-voids in the sub-layer of membrane morphology contributed to higher permeability. Numerous research groups have studied that the macro-voids structure in the sub-layer improved the volume flux of the prepared membrane $[10,11]$. Nevertheless, it was confirmed that this structure reduced the mechanical strength of the whole membrane by using special testing of this kind of mechanical strength. The addition of surfactants towards polymeric solutions altered the final structure of the fabricated membranes, thus in this study, three different surfactants are blended with other materials with the respective formulation and the finally membrane unique structures are finally analysed by analytical scanning electron microscopy.

In the molecular analysis, the existence of functional groups in the polymeric membrane can be measured by using a Fourier Transform Infrared Spectroscopy (FTIR). The results provide information on bonding vibration states of a molecule [16] in the membranes. Additionally, FTIR shows the changes of the functional group in the membrane by referring to the bands shifted in the FTIR spectra when the additional materials are blending into the polymeric solution. It is remarked that FTIR very convenient instrument to determine the molecular orientation and molecular interaction between the components in the samples. Several researchers used FTIR together with Attenuated Total Reflectance (ATR) in order to get more details on the surface and chemical structure of the components $[9,16,17]$.

Thermogravimetric analysis (TGA) is a method to identify the thermal stability of the sample by determining the changes of the sample mass as a function of temperature or time [18]. The changes of the mass could be in physical or chemical properties of the samples and the increase of temperature is in the constant heating rate during the process. Thermal stability of the membrane sample can be compared based on the TGA curves, by plotting the membrane samples weight loss against temperature or time. Several publications were reported about the basic of TGA curve. TGA curve can be expressed in three levels of weight changes. These levels of curves are including the stage of initial weight loss, thermal decomposition and sample degradation [18-22]. Generally, the first stage occurred due to the liberated of moisture (residual water) and other volatile components [21-23], which is depending on the sample compositions. It is also might be owing to the degradation of hard segments of the bond in the sample [20]. It was suggested that the loss of sample weight in the second stage corresponds to soft segment decomposition and the starting of polymer degradation [20, 23]. In this stage, it is also known as the main thermal degradation. Several researchers symbolized the final stage as the carbonization of the degraded products to ash $[18,21,22]$. The improvement of thermal stability for the prepared membrane with the addition of surfactant (SDS, Triton X-100 and Tween 80) in the polymer solutions using TGA is investigated.

Therefore, the aim of this paper is to deduce the major effects of surfactant materials on the performance and properties of PVDF based ultrafiltration membranes. Using of scanning electron microscopy (SEM), FTIR and TGA techniques, the evolution of morphologies, molecular alignment and thermal stability were characterized.

\section{Materials and method}

\subsection{Materials}

Polymer poly(vinylidene fluoride), PVDF (Kynar® from Arkema, $\mathrm{Mw}=45.00 \mathrm{~g} / \mathrm{mol}, \mathrm{d}=1.78 \mathrm{~g} / \mathrm{cm}^{3}$ ) was obtained in the form of pellet. N-methyl-2-pyrrolidone, (NMP > 99\%) 
used as the solvent (purchased from Merck, Darmstadt, Germany, $\mathrm{d}=1.00 \mathrm{~g} / \mathrm{cm}^{3}$ ). Polyethylene glycol, PEG 200 utilized as an additive in the polymeric membrane solution (supplied by Sigma Aldrich). Sodium dodecyl sulfate, SDS $(\mathrm{Mw}=288.37 \mathrm{~g} / \mathrm{mol})$ and Tween $80\left(\mathrm{~d}=1.060-1.090 \mathrm{~g} / \mathrm{cm}^{3}\right)$ (from Merck Schuchardt OHG, Germany) and Triton X-100 $(\mathrm{Mw}=646.86 \mathrm{~g} / \mathrm{mol}$ from Fisher Chemical) were used as surfactants. Ethanol, n-hexane and distilled water were used in the coagulation bath for post-treatment purposed. Bovine serum albumin (BSA, Mw $=69 \mathrm{kDa}$ ) and egg albu$\min (\mathrm{EA}, \mathrm{Mw}=45 \mathrm{kDa}$ ) (obtained from Acros Organics, USA) used as the solute for filtration test. Disodium hydrogen phosphate $\left(\mathrm{Na}_{2} \mathrm{HPO}_{4}\right)$ and sodium phosphate monobasic monohydrate $\left(\mathrm{NaH}_{2} \mathrm{PO}_{4} \cdot \mathrm{H}_{2} \mathrm{O}\right)$ were used for the preparation of protein feed solution.

For buffer solution, $1 \mathrm{~L}$ of $1 \mathrm{M} \mathrm{NaH}_{2} \mathrm{PO}_{4} \cdot \mathrm{H}_{2} \mathrm{O}$ (weak acid) and $\mathrm{Na}_{2} \mathrm{HPO}_{4}$ (the salt, conjugate base) were prepared individually by dissolving pre-weighed calculated amounts of each acid and conjugate base in sufficient $\mathrm{H}_{2} \mathrm{O} .158 \mathrm{ml}$ of $1 \mathrm{M}$ $\mathrm{NaH}_{2} \mathrm{PO}_{4} \cdot \mathrm{H}_{2} \mathrm{O}$ stock solution, $342 \mathrm{ml}$ of $1 \mathrm{M} \mathrm{Na}_{2} \mathrm{HPO}_{4}$ stock solution and sufficient $\mathrm{H}_{2} \mathrm{O}$ were mixed together to make $1 \mathrm{~L}$ of $0.5 \mathrm{M}$ phosphate buffer with $\mathrm{pH} 7.2$. BSA $(69 \mathrm{kDa})$ and EA ( $45 \mathrm{kDa})$ with concentration of $0.1 \mathrm{wt} \%$ were then slowly diluted in $0.5 \mathrm{M}$ phosphate buffer solution.

\subsection{Membrane fabrication}

The polymeric membrane solutions were obtained by blending of PVDF polymer and PEG 200 additive in NMP solvent under constant stirring for 8 hours at $55^{\circ} \mathrm{C}-60{ }^{\circ} \mathrm{C}$, in the presence of a surfactant. A series of polymer solutions were prepared by varying the types of surfactant as showed in Table 1. Then, the homogenous polymeric solution was standing for at least 2 hours to eliminate air bubbles before casting. The solutions were cast on a glass plate, with aid of casting knife maintaining a similar clearance or gap between the knife and the glass. Then, $180 \mu \mathrm{m}$ of membrane film on the glass plate immersed in a water bath (coagulation) and let the precipitation process to take place and complete. The casted films detached from the glass plate after some time and moved the film to new tap water for 1 day. The dry membranes were obtained after immersed the membrane in ethanol and n-hexane for 24 hours and 2 hours, respectively before drying at room temperature for at least 1 day. The membranes were cut into desired shape and size (circular disk form with diameter $42 \mathrm{~mm}$ ) to place inside the filtration cell. Membranes from different formulations were assigned as MG (without surfactant), MGS (with SDS), MGT (with Triton X-100) and MGW (with Tween 80) membranes.
Table 1 Formulation of PVDF based UF membranes

\begin{tabular}{cccccccc}
\hline \multirow{2}{*}{ Membrane } & PVDF & NMP & PEG & \multicolumn{3}{c}{ Surfactants $(w t \%)$} \\
\cline { 5 - 7 } & $($ wt\%) & $($ wt $\%)$ & $\begin{array}{c}200 \\
(\text { wt } \%)\end{array}$ & SDS & $\begin{array}{c}\text { Triton } \\
\text { X-100 }\end{array}$ & $\begin{array}{c}\text { Tween } \\
80\end{array}$ \\
\hline MG & 17 & 80 & 3 & 0 & 0 & 0 \\
MGS & 17 & 78 & 3 & 2 & 0 & 0 \\
MGT & 17 & 78 & 3 & 0 & 2 & 0 \\
MGW & 17 & 78 & 3 & 0 & 0 & 2 \\
\hline
\end{tabular}

\subsection{Performance evaluation}

The experimental work was performed in dead-end mode by using Solvent Resistant Stirred Cell (UF Cell-XFUF 047 01-Model, Milipore, USA) with a membrane diameter of $42 \mathrm{~mm}$, tighten with a rubber O-ring and a Teflon coated magnetic paddle. Effective area of the disk membranes is $1.3856 \times 10^{-3} \mathrm{~m}^{2}$. The fresh membranes were compacted for $30 \mathrm{~min}$ for stabilization before the actual performance is carried out. The effects of surfactants in PVDF UF membranes were investigated by performing protein separation (permeate flux and protein rejection).

The performance was operated under a steady state flow at $300 \mathrm{kPa}$ of transmembrane pressure with $250 \mathrm{ml}$ of protein samples. The protein experiment was conducted up to 1 hour of separation. The filtrate were collected and determined for protein solute concentration using UV-Vis spectrophotometer (wavelength $280 \mathrm{~nm}$ ). The experimental works were conducted with three times of analysis for triplication and all the experimental data of fluxes and rejection are the average values of the membranes performance. The permeate flux and protein rejection are calculated using Eq. (1) and Eq. (2), respectively.

$J v=\left(\frac{v}{A t}\right)$.

Where $J v$ is the permeate flux $\left(\mathrm{L} / \mathrm{m}^{2} \mathrm{~h}\right), v$ is the volume of permeate solution collected (L), $A$ is the effective area of membrane $\left(\mathrm{m}^{2}\right)$ and $t$ is the time (h).

$R=\left(1-\frac{C p}{C f}\right) \times 100$.

Where $R$ is rejection of protein (\%) is, $C p$ is the concentration of protein in permeates $(\mathrm{mg} / \mathrm{mL})$ and $C f$ is the concentration of protein in the feed $(\mathrm{mg} / \mathrm{mL})$.

\subsection{Morphological analysis}

The prepared membranes were analyzed using microscopic observation, carried out by Scanning Electron Microscope (SEM- JEOL JSM-6360LA). Morphological images 
captured at a range of magnifications (500X - 4000X) for cross-sectional views, after the samples were broken in liquid nitrogen and coated with gold, using Auto Fine Coater (JFC-1600). Membrane morphological details (pore lengths and widths) are the average values that measured from 15 measuring points based on the SEM images during the SEM analysis [24].

\subsection{Molecular study}

The molecular orientation of the membrane samples were analyzed using transmission Variance 3100 FTIR Excalibur Series. FTIR analyses were performed with 32 scans in total at a resolution of $2 \mathrm{~cm}^{-1}$. The samples placed on the sample holder and all the spectra were detected in the wave number of $4000-1000 \mathrm{~cm}^{-1}$.

\subsection{Thermogravimetric analysis (TGA)}

Thermal stability of the membrane samples monitored by the weight change occurred during the heating process. The Thermogravimetric analysis (TGA) details were obtained using an instrument Mettler Toledo Gas Controller GC 200. The samples heated up to $900{ }^{\circ} \mathrm{C}$ under the influence of nitrogen gas with constant heat rate and the changes in weight during the process were recorded.

\section{Result and discussion}

\subsection{Membrane performance}

Fig. 1 shows the permeate flux of PVDF-UF membranes with different surfactants. The main intention is to determine whether the surfactants, SDS, Triton X-100 and Tween 80, affect the performance of the ultrafiltration membranes. It is clearly shown in Fig. 1 that the addition of surfactant into the polymeric solution improved the performance of BSA and EA permeate flux. Permeate flux of PVDF membranes containing surfactant slightly increased from $2.74 \mathrm{~L} / \mathrm{m}^{2} \mathrm{~h}(\mathrm{MG})$ to $3.19 \mathrm{~L} / \mathrm{m}^{2} \mathrm{~h}(\mathrm{MGS})$ and $8.84 \mathrm{~L} / \mathrm{m}^{2} \mathrm{~h}(\mathrm{MGT})$ for BSA protein and from $1.03 \mathrm{~L} / \mathrm{m}^{2} \mathrm{~h}$ (MG) to $1.19 \mathrm{~L} / \mathrm{m}^{2} \mathrm{~h}$ (MGS) and $2.25 \mathrm{~L} / \mathrm{m}^{2} \mathrm{~h}$ (MGT) for EA protein. Meanwhile, MGW membrane shows significant improvement in the permeate fluxes which are from $2.74 \mathrm{~L} / \mathrm{m}^{2} \mathrm{~h}$ to $78.14 \mathrm{~L} / \mathrm{m}^{2} \mathrm{~h}$ and $1.03 \mathrm{~L} / \mathrm{m}^{2} \mathrm{~h}$ to $15.58 \mathrm{~L} / \mathrm{m}^{2} \mathrm{~h}$ for BSA and EA, respectively.

The experimental data obtained are aligned with other research that the surfactants significantly affected the permeation, properties and morphology of membrane [25]. As observed on the line graph, it can be asserted that BSA permeate flux is higher than EA flux. As the molecular weights $(\mathrm{Mw})$ of the protein solutes are different,

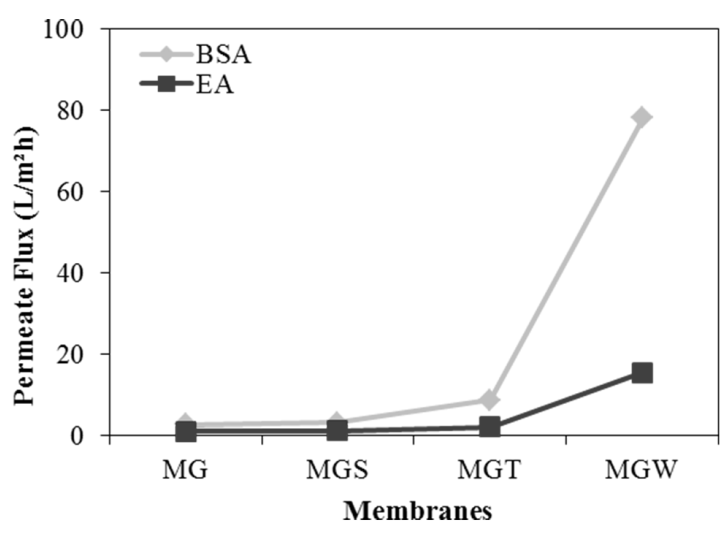

Fig. 1 Permeate flux of PVDF-UF membranes with SDS / Triton X-100 / Tween 80

which are $69 \mathrm{kDa}(\mathrm{BSA})$ and $45 \mathrm{kDa}$ (EA) hence the BSA achieved a higher result. Nevertheless, the trends of both proteins are similar. Moreover, the high permeate flux might relate to the morphology of the prepared membranes as will explain in SEM section. Fadilah and Hassan have mentioned that higher permeate flux is due to the development of macro-voids cavities in the support or sub-layer of the membrane, and then increased the permeation of the membrane [13].

Fig. 2 depicted the BSA and EA rejection by PVDF-UF membranes with the presence of different surfactants. PVDF membrane with the absence of surfactant (MG) achieved the highest protein rejection for both proteins, which are $85 \%$ and $78 \%$ for BSA and EA, respectively. In addition, the rejection of all PVDF-UF membranes containing surfactant showed a small reduction. This phenomenon might be due to the formation finger-like pores and larger macro-voids beneath the membranes. Apart from that, it was stated that the decrement of the membrane performance can be explained by the existence of macro-voids and larger diameter in the sub-layer resulting from the addition of surfactant [17].

\subsection{Morphological details}

Figs. 3 to 6 show the cross-sectional images of the PVDF-UF membranes with the addition of different surfactant. In general, all membranes exhibited typical asymmetrical structures of dense skin and dense support layer. The addition of PEG 200 (hydrophilic additive) into the polymeric solution promotes the extension of larger macro-voids within the sub-layer due to the instantaneous de-mixing and thermodynamic instability of the nascent film during the phase inversion [26]. Besides, the weak miscibility of PVDF polymer and non-solvent during the phase inversion encouraged the 


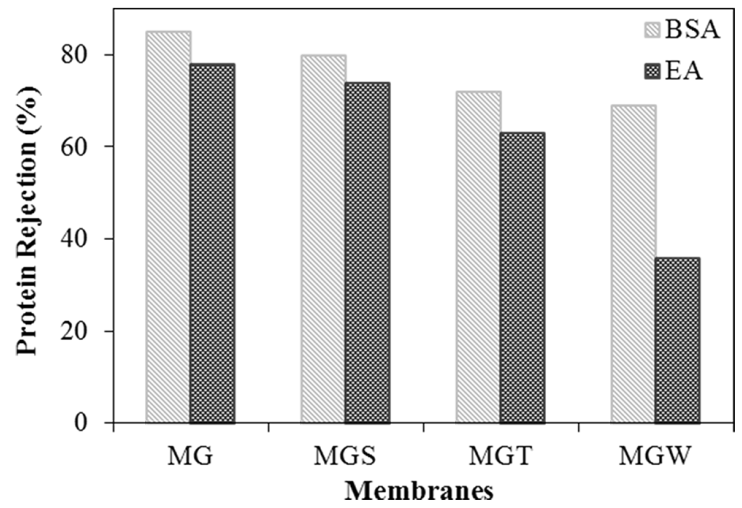

Fig. 2 Rejection of BSA and EA of PVDF-UF membranes with SDS / Triton X-100 / Tween 80

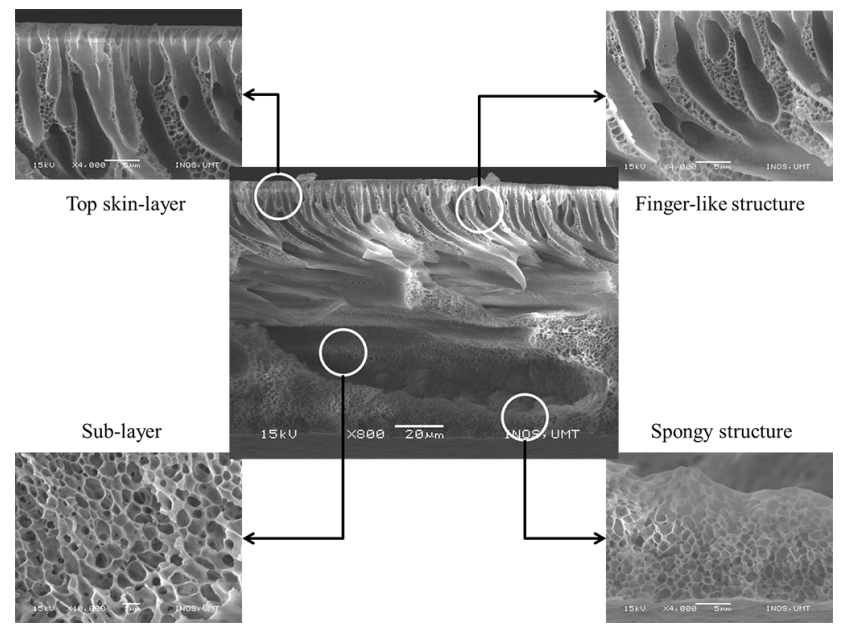

Fig. 3 Cross-sectional image of MG membrane (without surfactant)

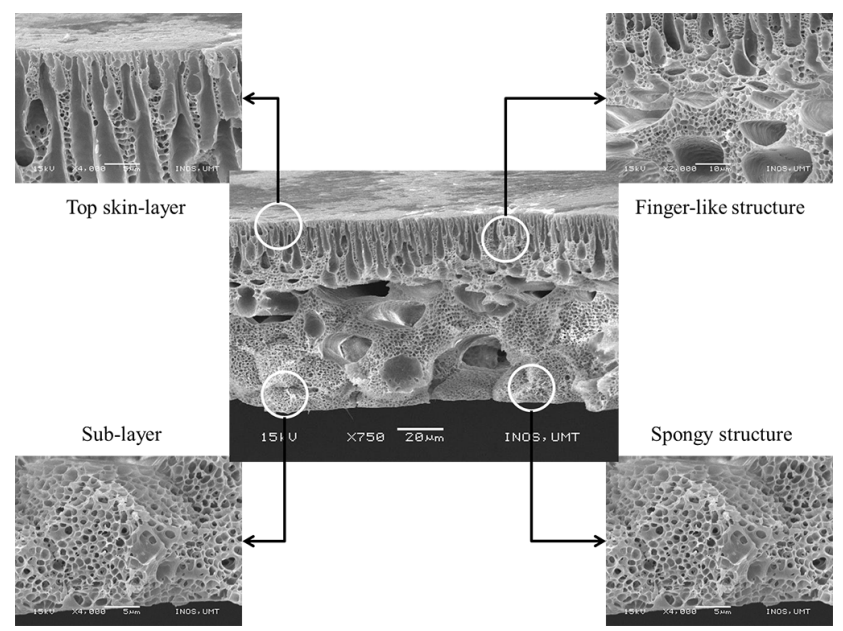

Fig. 4 Cross-sectional image of MGS membrane (SDS)

membrane thickness which leads toward better rejection up to $85 \%$ and $78 \%$ for BSA and EA, respectively.

Fig. 4 illustrates the morphological structure of blend membrane, which is MGS membrane with the presence of

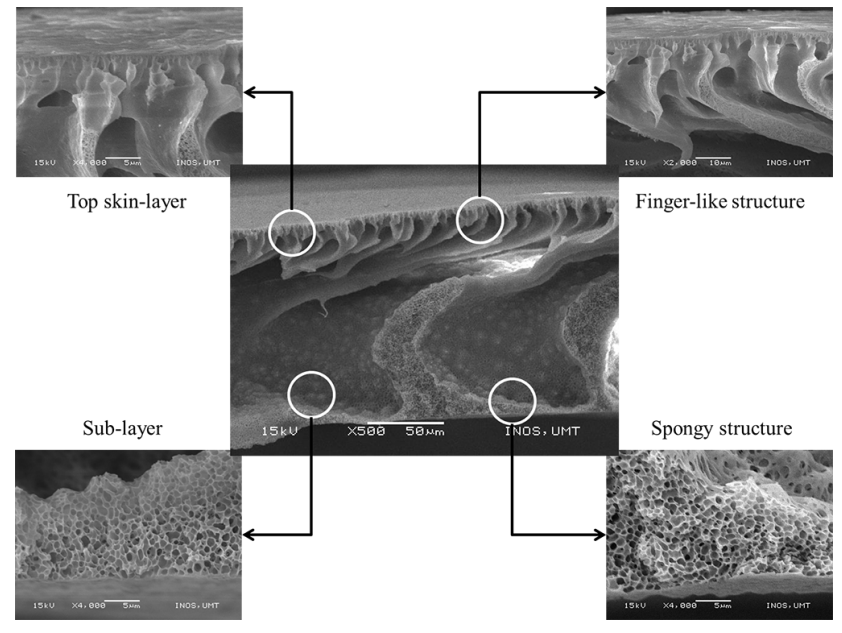

Fig. 5 Cross-sectional image of MGT membrane (Triton X-100)

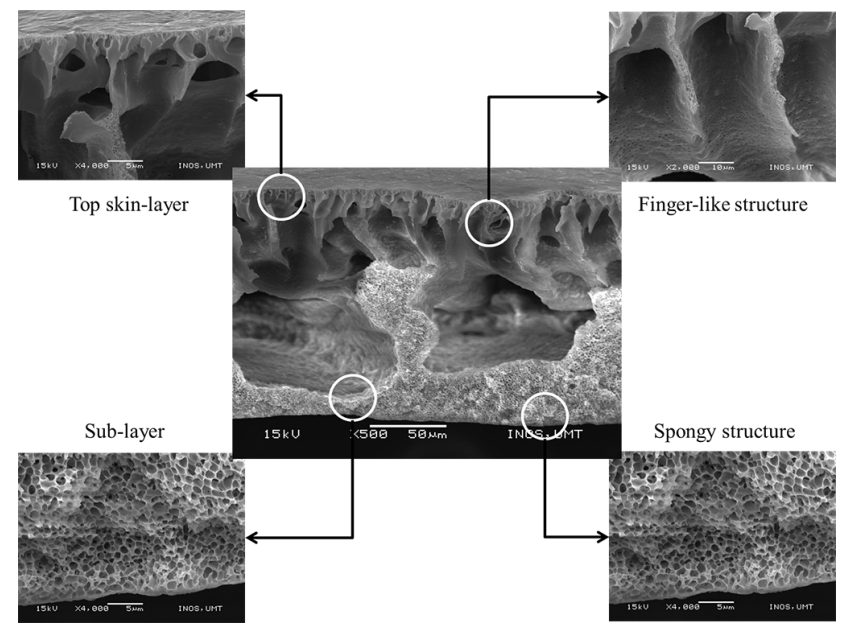

Fig. 6 Cross-sectional image of MGW membrane (Tween 80)

$2 \mathrm{wt} \%$ of SDS. The images revealed that a small amount of SDS in the polymeric solution favors the formation of porous structure, small macro-voids and dense spongy sublayer inside the membrane. Small pore width and finger-like structures were fully growth beneath the top skin layer that connected to high selectivity, which higher than other PVDF-surfactant membranes (BSA, $80 \%$; EA, $74 \%$ ) and high permeability, which higher than MG membrane (BSA, $3.19 \mathrm{~L} / \mathrm{m}^{2} \mathrm{~h}$; EA $1.19 \mathrm{~L} / \mathrm{m}^{2} \mathrm{~h}$ ). Analysis data on morphologies were found to be in line with the previous results. Rahimpour and his co-worker reported that small amount of SDS has possibility to cause the reduction solvent evaporation rate and a relapse of polymer chain interaction arisen [1], thus diminished the growth of skin layer and at the same time enhanced the finger-like pores inside the membrane.

Figs. 5 and 6 represent the cross-sectional images of MGT membrane with $2 \mathrm{wt} \%$ of Triton X-100 and MGW with 
$2 \mathrm{wt} \%$ of Tween 80 , respectively. Referring to these SEM images, larger macro-voids and more finger-like structures were discovered than MG membrane when Triton X-100 and Tween 80 are added to the respective membrane solutions. These configurations justify the experimental data obtained by both membranes in BSA permeate flux, which is $78.14 \mathrm{~L} / \mathrm{m}^{2} \mathrm{~h}$ and $8.84 \mathrm{~L} / \mathrm{m}^{2} \mathrm{~h}$ for MGW and MGT membrane, respectively. In addition, it was mentioned that $2 \mathrm{wt} \%$ of Triton X-100 provided larger finger-like pores in the sublayer and Tween 80 in the solution enlarged the macro-voids [1]. From the interpretation, it shows that morphological structure corresponds to the performance of the membrane.

Table 2 shows the details of PVDF-UF membranes structures with different types of surfactant. The addition of surfactants toward PEG additives in the PVDF membranes has reduced the length of macro-voids; improved the length of pores and width of pores and finger-like structures. The largest pores size was dominated by MGW membrane with $1.35 \mu \mathrm{m}$ length and $1.44 \mu \mathrm{m}$ widths, which reflected towards the highest permeability. The smallest sizes of pores lead towards higher protein rejection, which viewed by MG membrane with $85 \%$ and $78 \%$ of BSA and EA protein rejection, respectively.

\subsection{Molecular analysis}

Figs. 7 to 10 show the IR spectra of PVDF-UF control and modified membranes with different surfactant towards PEG 200 additive. The results showed that all membranes exhibited similar infrared transmittance bands at the wavenumber range of $800-1700 \mathrm{~cm}^{-1}$. This was due to the same basic structure of PVDF polymer and PEG 200 additive after modification with surfactants. For example, C-F stretch appeared at $1174 \sim 1182 \mathrm{~cm}^{-1}$ (alkyl halide group) and C-C-C asymmetric vibrational at $880 \mathrm{~cm}^{-1}$ that come from PVDF polymer. Moreover, a significant peak detected at $1070 \mathrm{~cm}^{-1}$ is corresponded to $\mathrm{C}-\mathrm{O}=\mathrm{C}$ bonds. At of $1650 \sim 1672 \mathrm{~cm}^{-1}$, these bands are assigned to $\mathrm{C}=\mathrm{C}$ bond attributed to $\mathrm{PEG} 200$ additive molecules in the analyzed membranes.

Table 2 Membrane morphological details for PVDF / PEG / surfactants membranes

\begin{tabular}{lcccccc}
\hline Membrane & $\begin{array}{c}\text { Finger- } \\
\text { like } \\
\text { Length } \\
(\mu \mathrm{m})\end{array}$ & $\begin{array}{c}\text { Finger- } \\
\text { like } \\
\text { Width } \\
(\mu \mathrm{m})\end{array}$ & $\begin{array}{c}\text { Macro- } \\
\text { voids } \\
\text { Length } \\
(\mu \mathrm{m})\end{array}$ & $\begin{array}{c}\text { Macro- } \\
\text { voids } \\
\text { Width } \\
(\mu \mathrm{m})\end{array}$ & $\begin{array}{c}\text { Pore } \\
\text { Length } \\
(\mu \mathrm{m})\end{array}$ & $\begin{array}{c}\text { Pore } \\
\text { Width } \\
(\mu \mathrm{m})\end{array}$ \\
\hline MG & 40.9 & 4.1 & 130.1 & 26.6 & 1.11 & 1.18 \\
MGS & 30.3 & 6.4 & 28.9 & 13.2 & 1.19 & 1.25 \\
MGT & 90.0 & 26.8 & 99.8 & 73.0 & 1.25 & 1.29 \\
MGW & 25.3 & 4.5 & 115.3 & 68.2 & 1.35 & 1.44 \\
\hline
\end{tabular}

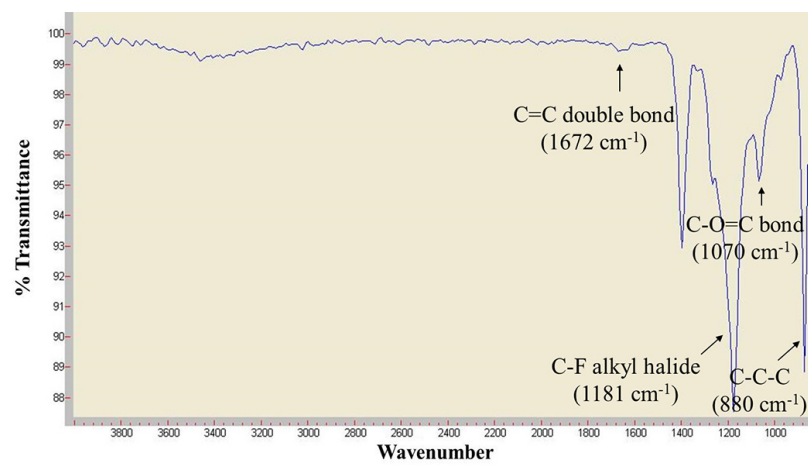

Fig. 7 FTIR spectra of MG membranes (without surfactant)

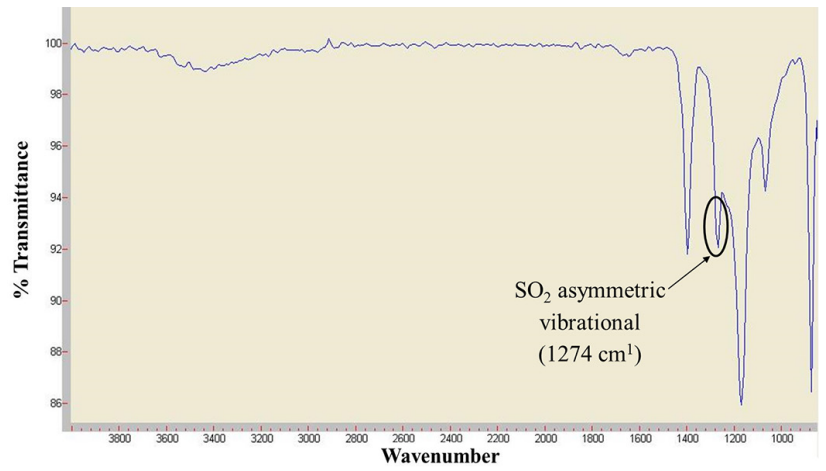

Fig. 8 FTIR spectra of MGS membranes (SDS)

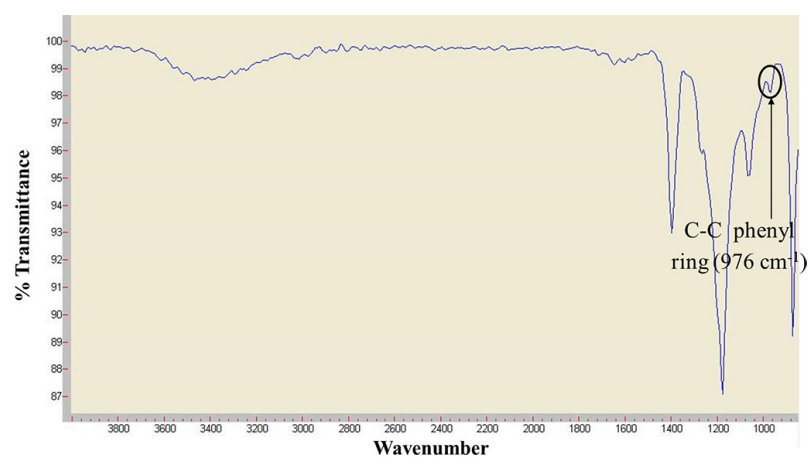

Fig. 9 FTIR spectra of MGT membranes (Triton X-100)

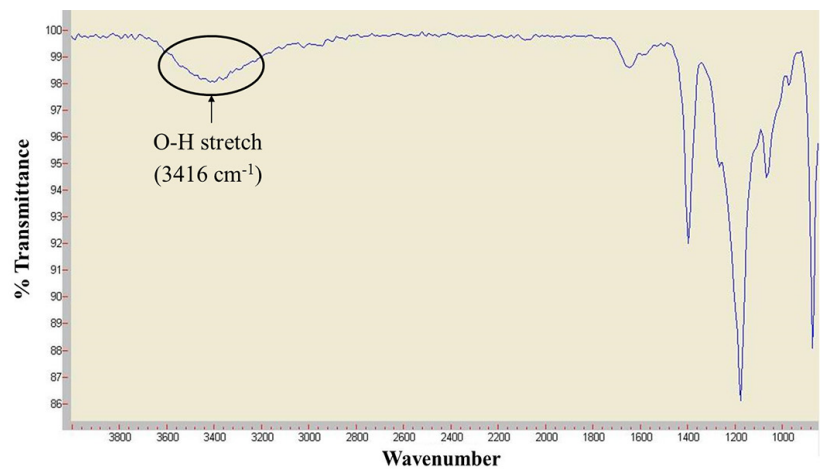

Fig. 10 FTIR spectra of MGW membranes (Tween 80) 
Fig. 8 is the IR spectra of MGS membrane. From the figure, MGS membrane has similar spectra as control membrane (Fig. 7) due to the basic materials formula used. By comparing these two figures, a new transmittance band appeared at $1274 \mathrm{~cm}^{-1}$, which belongs to $\mathrm{S}=\mathrm{O}$ asymmetrical stretch from sulfone group [27] when a small amount of SDS surfactant added into the polymeric solution. Apart from that, MGT membrane also has similar spectra as MG membrane as shown in Fig. 9. The intensity of $\mathrm{C}=\mathrm{C}$ stretch from alkene group in its phenyl ring was observed at the wavenumber of $976 \mathrm{~cm}^{-1}$, this lead to the confirmation of the presence surfactant, Triton X-100 in the membrane film.

On the other hand, no significant peak observed for MGW (Tween 80) membrane as displayed in Fig. 10. Nevertheless, a strong absorption band of $\mathrm{O}-\mathrm{H}$ bond at a wavenumber of $3416 \mathrm{~cm}^{-1}$ appeared broadly, which belongs to Tween 80 . This is because of the structure of Tween 80 introduces triple additional $\mathrm{O}-\mathrm{H}$ groups per molecule in the polymeric solution. Overall, these IR spectra data confirm the changes in the surface chemistry of the membranes when different surfactants were blending in the polymeric solution and at the same time, these revelations correspond to the enhancement of the permeability and performance of the membranes.

\subsection{Thermogravimetric analysis (TGA)}

The thermogravimetric analysis provides supporting evidence for the interaction between PVDF polymer, PEG 200 and surfactant (SDS, Triton X-100, Tween 80) in the dope solution. By measuring the weight loss of the samples during the process, combination graphs plotted as in Fig. 11. This figure represents TGA curve of PVDF-UF membranes with addition different surfactants, which correspond to the dehydration and decomposition of the samples. It was mentioned that the materials with a strong bond between the particles could be spilled at high temperature [28]. Therefore, the samples were heated up to $900{ }^{\circ} \mathrm{C}$ and under the influence of nitrogen gas.

Based on Fig. 11, the total weight loss of MG, MGS, MGT and MGW membranes keep increased with increasing of reaction time. There are no significant changes in the trend of samples decomposition. From the graph, stages of the weight loss can be divided into three levels. The first weight loss is about 5, 6 and $4 \%$ for MGS, MGT and MGW membranes, respectively and credited to the loss of surface-adsorbed water that occurred between the room temperature up to $400{ }^{\circ} \mathrm{C}$. In other words, water loss from the membrane surface within this range of temperature. Due to the weak electrostatic interaction between the

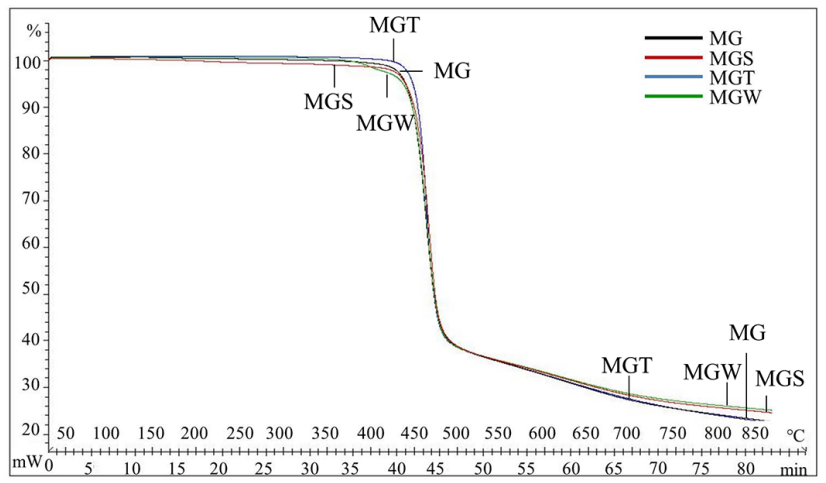

Fig. 11 TGA curves for PVDF-UF membranes without (MG) and with different surfactants (MGS, MGT, MGW)

polymer chains, the second level of weight loss occurred at the range of $400-500{ }^{\circ} \mathrm{C}$ and the loss is about 66,66 and $64 \%$ for MGS, MGT and MGW membrane, respectively. It was stated that the second stage of weight loss is implied to the main thermal degradation [22].

The last stage might be owing to the degradation of the main chain in the polymer [29]. It is also known as the carbonization of the degraded products to ash [19, 22, 23]. The third loss appeared at the range of $550-580{ }^{\circ} \mathrm{C}$ and about 75,76 and $76 \%$ of MGS, MGT and MGW samples, respectively. As can be seen from the graph, MGS membrane with containing SDS surfactant is the most stable membrane in term of thermal stability. The formation of complex-sulphonate with counter-ions in MGS membrane resulted in minimum weight loss during the decomposition process.

\section{Conclusion}

The effects of SDS, Triton X-100 and Tween 80 in the polymeric PVDF UF membranes were examined. The addition of these surfactants as additives produced asymmetrical PVDF-surfactant membranes with the improved of membrane flux and well characters of pores. Best to our knowledge, such findings was not yet reported by any researchers. Experimental data discovered that, the addition of $2 \mathrm{wt} \%$ of Tween 80 (MGW) increased membrane flux up to $2751.8 \%$ compared to the membrane without surfactant (MG) membrane. Moreover, surfactants also led towards fine evolutions of membrane pores with good separation capability. In addition, the incorporated surfactants produced fine alignment, good molecular orientation and having better thermal stability. Therefore, this study proved that the surfactant materials played important roles in determining the membrane performance and properties which is critical beneficial towards membrane modifications and improvement. 


$\begin{array}{ll}\text { Abbreviations } & \\ \text { ATR } & \text { Attenuated total reflectance } \\ \text { BSA } & \text { Bovine serum albumin } \\ \text { DMAc } & \text { Dimethylacetamide } \\ \text { DMF } & \text { Dimethylformamide } \\ \text { DMSO } & \text { Dimethyl sulfoxide } \\ \text { DSC } & \text { Differential scanning calorimetry } \\ \text { EA } & \text { Egg albumin } \\ \text { FTIR } & \text { Fourier transform infrared spectroscopy } \\ \text { MG } & \text { Membrane (PVDF-PEG) } \\ \text { MGS } & \text { Membrane (PVDF-PEG/SDS) } \\ \text { MGT } & \text { Membrane (PVDF-PEG/Triton X-100) } \\ \text { MGW } & \text { Membrane (PVDF-PEG/Tween 80) } \\ \text { NMP } & \text { N-methyl-2-pyrrolidone } \\ \text { PEG } & \text { Polyethylene glycol }\end{array}$

\section{References}

[1] Rahimpour, A., Madaeni, S. S., Mansourpanah, Y. "The effect of anionic, non-ionic and cationic surfactants on morphology and performance of polyethersulfone ultrafiltration membranes for milk concentration", Journal of Membrane Science, 296(1-2), pp. 110-121, 2007.

https://doi.org/10.1016/j.memsci.2007.03.029

[2] Amirilargani, M., Saljoughi, E., Mohammadi, T. "Effects of Tween 80 concentration as a surfactant additive on morphology and permeability of flat sheet polyethersulfone (PES) membranes", Desalination, 249(2), pp. 837-842, 2009.

https://doi.org/10.1016/j.desal.2009.01.041

[3] Zhou, J., Ren, J., Lin, L., Deng, M. "Morphology evolution of thickness-gradient membranes prepared by wet phase-inversion process", Separation and Purification Technology, 63(2), pp. 484-486, 2008. https://doi.org/10.1016/j.seppur.2008.05.019

[4] Sadrzadeh, M., Bhattacharjee, S. "Rational design of phase inversion membranes by tailoring thermodynamics and kinetics of casting solution using polymer additives", Journal of Membrane Science, 441, pp. 31-44, 2013.

https://doi.org/10.1016/j.memsci.2013.04.009

[5] Salahi, A., Mohammadi, T., Behbahani, R. M., Hemmati, M. "Asymmetric polyethersulfone ultrafiltration membranes for oily wastewater treatment: Synthesis, characterization, ANFIS modeling, and performance", Journal of Environmental Chemical Engineering, 3(1), pp. 170-178, 2015.

https://doi.org/10.1016/j.jece.2014.10.021

[6] Madaeni, S. S., Rahimpour, A. "Effect of type of solvent and non-solvents on morphology and performance of polysulfone and polyethersulfone ultrafiltration membranes for milk concentration", Polymers Advanced Technologies, 16(10), pp. 717-724, 2005. https://doi.org/10.1002/pat.647

[7] Rahimpour, A., Madaeni, S. S., Mehdipour-Ataei, S. "Synthesis of a novel poly(amide-imide) (PAI) and preparation and characterization of PAI blended polyethersulfone (PES) membranes", Journal of Membrane Science, 311(1-2), pp. 349-359, 2008.

https://doi.org/10.1016/j.memsci.2007.12.038

$\begin{array}{ll}\text { PES } & \text { Polyethersulfone } \\ \text { PSF } & \text { Polysulfone } \\ \text { PVDF } & \text { Polyvinylidene fluoride } \\ \text { SDS } & \text { Sodium dodecyl sulphate } \\ \text { SEM } & \text { Scanning electron microscopy } \\ \text { TGA } & \text { Thermogravimetric analysis } \\ \text { UF } & \text { Ultrafiltration } \\ \text { UV-Vis } & \text { Ultraviolet visible spectrophotometer }\end{array}$

\section{Acknowledgement}

The authors wish to express their gratitude to the Research Management \& Innovation Centre (RMIC), Universiti Sultan Zainal Abidin (UniSZA) for financing the research project under DPU Research Grant Scheme.

[8] Guillen, G. R., Pan, Y., Li, M., Hoek, E. M. V. "Preparation and Characterization of Membranes Formed by Nonsolvent Induced Phase Separation: A Review", Industrial \& Engineering Chemistry Research, 50(7), pp. 3798-3817, 2011. https://doi.org/10.1021/ie101928r

[9] Rahimpour, A., Madaeni, S. S. "Improvement of performance and surface properties of nano-porous polyethersulfone (PES) membrane using hydrophilic monomers as additives in the casting solution", Journal of Membrane Science, 360(1-2), pp. 371-379, 2010. https://doi.org/10.1016/j.memsci.2010.05.036

[10] Hassan, A. R., Munaim, M. S. A. "Fabrication and characterization of integrally skinned-oriented highly selective charged asymmetric low pressure poly(ether sulfone) membranes for nanofiltration", Journal of Chemical Technology and Biotechnology, 87(4), pp. 559-569, 2012.

https://doi.org/10.1002/jctb.2751

[11] Moghareh Abed, M. R., Kumbharkar, S. C., Groth, A. M., Li, K. "Economical production of PVDF-g-POEM for use as a blend in preparation of PVDF based hydrophilic hollow fibre membranes", Separation and Purification Technology, 106, pp. 47-55, 2013. https://doi.org/10.1016/j.seppur.2012.12.024

[12] Zhao, C., Xu, X., Chen, J., Yang, F. "Effect of graphene oxide concentration on the morphologies and antifouling properties of PVDF ultrafiltration membranes", Journal of Environmental Chemical Engineering, 1(3), pp. 349-354, 2013.

https://doi.org/10.1016/j.jece.2013.05.014

[13] Md Fadilah, N. I., Hassan, A. R. "Preparation, Characterization and Performance Studies of Active PVDF Ultrafiltration-Surfactants Membranes Containing PVP as Additive", Advanced Materials Research, 1134, pp. 44-49, 2016.

https://doi.org/10.4028/www.scientific.net/AMR.1134.44

[14] Hwang, K.-J., Chiang, Y.-C. "Comparisons of membrane fouling and separation efficiency in protein / polysaccharide cross-flow microfiltration using membranes with different morphologies", Separation and Purification Technology, 125, pp. 74-82, 2014. https://doi.org/10.1016/j.seppur.2014.01.041 
[15] Kanani, D. M., Sun, X., Ghosh, R. "Reversible and irreversible membrane fouling during in-line microfiltration of concentrated protein solutions", Journal of Membrane Science, 315(1-2), pp. 1-10, 2008. https://doi.org/10.1016/j.memsci.2008.01.053

[16] Basri, H., Ismail, A. F., Aziz, M. "Polyethersulfone (PES)-silver composite UF membrane: Effect of silver loading and PVP molecular weight on membrane morphology and antibacterial activity", Desalination, 273(1), pp. 72-80, 2011. https://doi.org/10.1016/j.desal.2010.11.010

[17] Vatsha, B., Ngila, J. C., Moutloali, R. M. "Preparation of antifouling polyvinylpyrrolidone (PVP 40K) modified polyethersulfone (PES) ultrafiltration (UF) membrane for water purification", Physics and Chemistry of the Earth, Parts A/B/C, 67-69, pp. 125-131, 2014. https://doi.org/10.1016/j.pce.2013.09.021

[18] Zafar, M., Ali, M., Khan, S. M., Jamil, T., Butt, M. T. Z. "Effect of additives on the properties and performance of cellulose acetate derivative membranes in the separation of isopropanol / water mixtures", Desalination, 285, pp. 359-365, 2012. https://doi.org/10.1016/j.desal.2011.10.027

[19] Nirmala, L. R., Prakash, J. T. J. "Effect of lithium chloride on spectral, optical, thermal and mechanical behaviour of bis thiourea zinc acetate crystals", Spectrochimica Acta Part A: Molecular and Biomolecular Spectroscopy, 97, pp. 673-677, 2012. https://doi.org/10.1016/j.saa.2012.07.008

[20] Chiu, H. T., Lin, J. M., Cheng, T. H., Chou, S. Y. "Fabrication of electrospun polyacrylonitrile ion-exchange membranes for application in lysozym", eXPRESS Polymer Letters, 5(4), pp. 308-317, 2011. https://doi.org/10.3144/expresspolymlett.2011.31

[21] Hazarika, J., Kumar, A. "Controllable synthesis and characterization of polypyrrole nanoparticles in sodium dodecylsulphate (SDS) micellar solutions", Synthetic Metals, 175, pp. 155-162, 2013. https://doi.org/10.1016/j.synthmet.2013.05.020

[22] Ali, M., Zafar, M., Jamil, T., Butt, M. T. Z. "Influence of glycol additives on the structure and performance of cellulose acetate / zinc oxide blend membranes", Desalination, 270(1-3), pp. 98-104, 2011. https://doi.org/10.1016/j.desal.2010.11.027
[23] Omastová, M., Trchová, M., Kovářová, J., Stejskal, J. "Synthesis and structural study of polypyrroles prepared in the presence of surfactants", Synthetic Metals, 138(3), pp. 447-455, 2003. https://doi.org/10.1016/S0379-6779(02)00498-8

[24] Fadilah, N. I. M. "Effect of surfactants on pore structure and pore properties of phase inversion ultrafiltration (UF) membrane", Master, Universiti Sains Islam Malaysia, 2015.

[25] Mansourpanah, Y., Alizadeh, K., Madaeni, S. S., Rahimpour, A., Soltani Afarani, H. "Using different surfactants for changing the properties of poly(piperazineamide) TFC nanofiltration membranes", Desalination, 271(1-3), pp. 169-177, 2011. https://doi.org/10.1016/j.desal.2010.12.026

[26] Wongchitphimon, S., Wang, R., Jiraratananon, R., Shi, L., Loh, C. H. "Effect of polyethylene glycol (PEG) as an additive on the fabrication of polyvinylidene fluoride-co-hexafluropropylene (PVDFHFP) asymmetric microporous hollow fiber membranes", Journal of Membrane Science, 369(1-2), pp. 329-338, 2011. https://doi.org/10.1016/j.memsci.2010.12.008

[27] Saedi, S., Madaeni, S. S., Shamsabadi, A. A., Mottaghi, F. "The effect of surfactants on the structure and performance of PES membrane for separation of carbon dioxide from methane", Separation and Purification Technology, 99, pp. 104-119, 2012. https://doi.org/10.1016/j.seppur.2012.08.028

[28] Bastami, T. R., Entezari, M. H., Hu, Q. H., Hartono, S. B., Qiao, S. Z. "Role of polymeric surfactants on the growth of manganese ferrite nanoparticles", Chemical Engineering Journal, 210, pp. 157-165, 2012. https://doi.org/10.1016/j.cej.2012.08.031

[29] Eren, E., Sarihan, A., Eren, B., Gumus, H., Kocak, F. O. "Preparation, characterization and performance enhancement of polysulfone ultrafiltration membrane using PBI as hydrophilic modifier", Journal of Membrane Science, 475, pp. 1-8, 2015. https://doi.org/10.1016/j.memsci.2014.10.010 